\title{
Construindo um Densímetro
}

\author{
(Making a didactic densimeter) \\ Rodrigo Ricetti \\ Departamento de Física, Universidade Federal do Paraná \\ CP 19044 CEP 81531-990 Curitiba, Paraná \\ ricetti@fisica.ufpr.br
}

Recebido em 14 de fevereiro, 2002. Aceito em 6 de agosto, 2002.

\begin{abstract}
Para fins didáticos, é apresentada uma maneira de construir um densímetro, aparelho utilizado para medir a densidade de fluidos. É um aparato fácil de ser construído e muito simples de ser utilizado. Sua principal vantagem sobre os densímetros que comercialmente encontramos, é a sua capacidade de medir a densidade de quaisquer líquidos, operando em qualquer faixa de densidade. Outra vantagem que apresenta, é a possibilidade de fazer uma medição relativa entre quaisquer líquidos, não fazendo apenas a medição relativa à densidade da água. Desta maneira, pode-se medir, por exemplo, a densidade do mercúrio em relação ao éter, com este instrumento. Nota-se que, desta maneira, com apenas um instrumento determina-se a densidade de qualquer líquido, não sendo necessário dispor-se de densímetros que operem em diversas faixas de densidade, como é o caso dos instrumentos encontrados comercialmente.
\end{abstract}

A didactic, inexpensive and easy-to-make densimeter is proposed. The main pedagogical advantage of this equipment is the possibility of exploring several situations involving the measurements in a wide range of densities for several kinds of liquids. It is also possible to measure the density of a given liquid with respect to any other kind of liquid, not only with respect to the water as usual in the more accessible densimeters.

\section{Introdução}

Uma das características dos fluidos é sua massa específica ou densidade, que determina algumas de suas propriedades. Em geral, um densímetro funciona comparando a densidade de qualquer fluido com a água.

Com o objetivo de tentar descobrir um meio de medir a densidade de qualquer líquido em relação a outro (e não apenas compará-lo com a água), apresenta-se abaixo o processo de construção de um densímetro simples, que funciona com dois líquidos quaisquer e opera em qualquer faixa de densidade. Com um instrumento razoavelmente simples como este, pode-se resolver a maior parte dos problemas envolvendo a determinação da densidade de fluidos que possamos encontrar em nosso dia-a-dia.

\section{Para a construção deste apa- rato deveremos dispor dos se- guintes materiais}

- uma pequena placa de acrílico de cerca de $10 \mathrm{~cm} \mathrm{x}$ $3,5 \mathrm{~cm}$ (pode ser obtido de um esquadro ou régua quebrada);
- uma seringa de $5 \mathrm{ml}$;

- mangueira 4x1mm $(50 \mathrm{~cm})$;

- conexão tipo "T" ( utilizada em automóveis );

- 2 parafusos M4 x $12 \mathrm{~mm}$ com porcas e arruelas;

- 2 parafusos M2,5 x $12 \mathrm{~mm}$ com porcas;

- 6 presilhas plásticas;

- 2 escalas técnicas (réguas) de $15 \mathrm{~cm}$.

\section{Construção}

O primeiro passo é marcar a placa de acrílico para fazer os furos para a fixação das duas réguas com os parafusos M4 x $12 \mathrm{~mm}$, como mostrado na figura 1 .

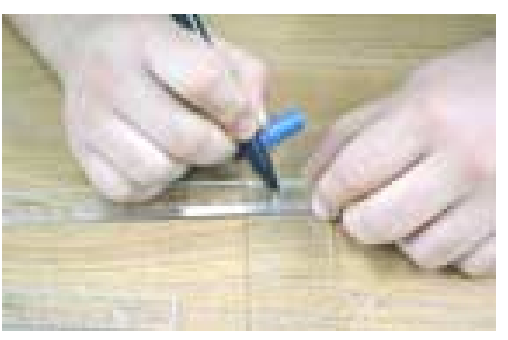

Figura 1. Marcação do acrílico. 
Uma vez feita a marcação com a caneta para retro projetor, deve-se puncionar em cima das marcas para facilitar a furação, como é mostrado na figura 2 .

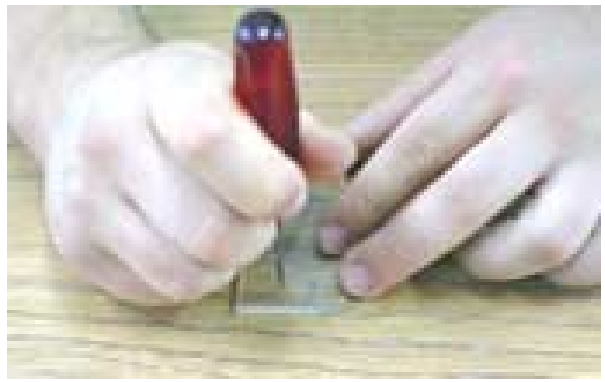

Figura 2. Punção: preparo para a furação.

A furação deve ser feita de maneira progressiva, ou seja, aumentando o diâmetro da broca gradativamente, a fim evitar trincas na peça de acrílico (figura 3 ).

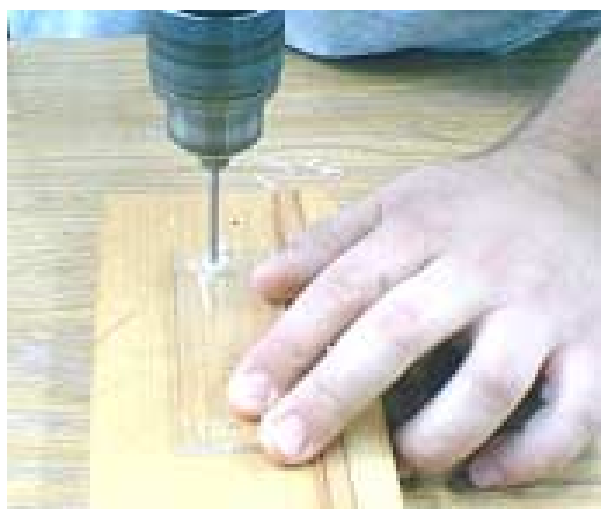

Figura 3. Furação gradual da Peça de Acrílico.

Uma vez feita a furação, deve-se parafusar as réguas na placa de acrílico, tomando o cuidado de verificar que os componentes fiquem no esquadro (figura 4).

Uma vez esquadrejado, deve-se furar o conjunto réguas/placa para passar os parafusos M2,5 x $12 \mathrm{~mm}$, que irão assegurar ao conjunto uma maior rigidez, como é mostrado na figura 5 .

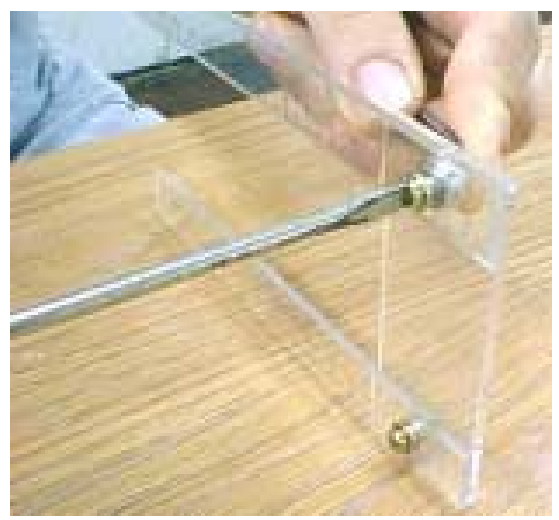

Figura 4. Fixação das réguas no acrílico.

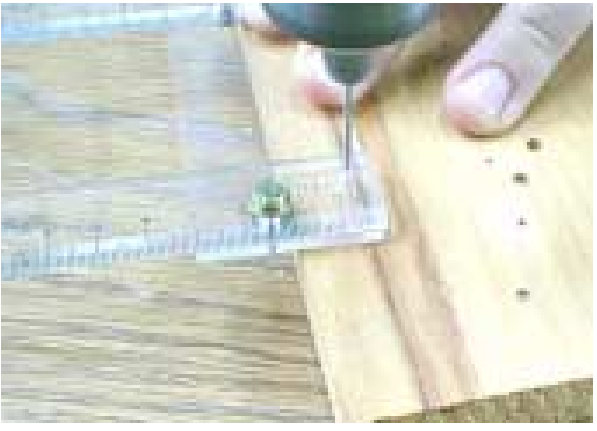

Figura 5. Esquadrejamento do conjunto réguas/placa.

O passo seguinte é conectar as mangueiras na conexão em "T" (figura 6) e marcar com a caneta para retro projetor a posição em que devem ser feitos os furos na placa de acrílico para fixar o conjunto mangueiras/conexão.

Basta, agora, prender o conjunto mangueiras/conexão no conjunto réguas/placa com as presilhas plásticas (figura 7) e instalar a seringa na ponta da mangueira que fica solta.

A forma final do instrumento é apresentada na figura 8 .

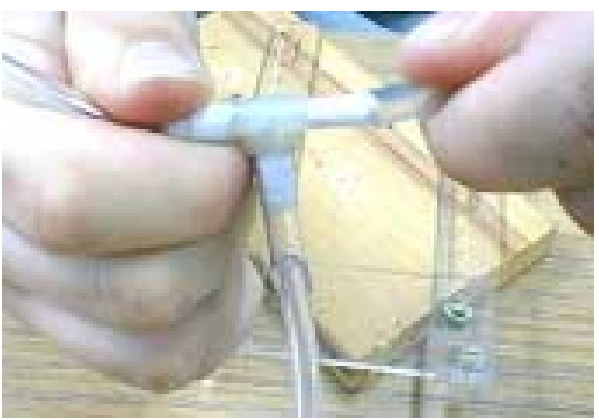

Figura 6. Conexão das mangueiras.

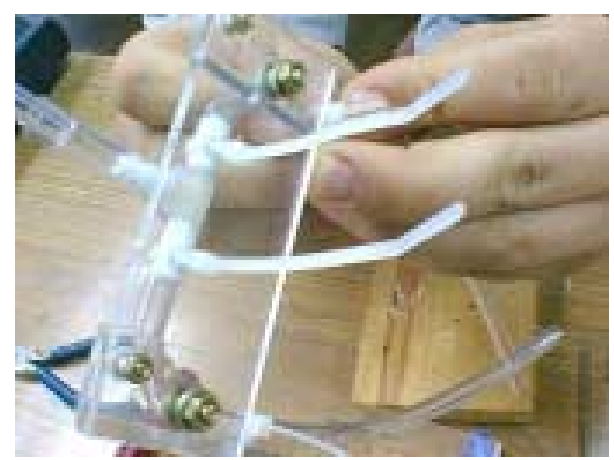

Figura 7. Fixação das mangueiras na estrutura. 


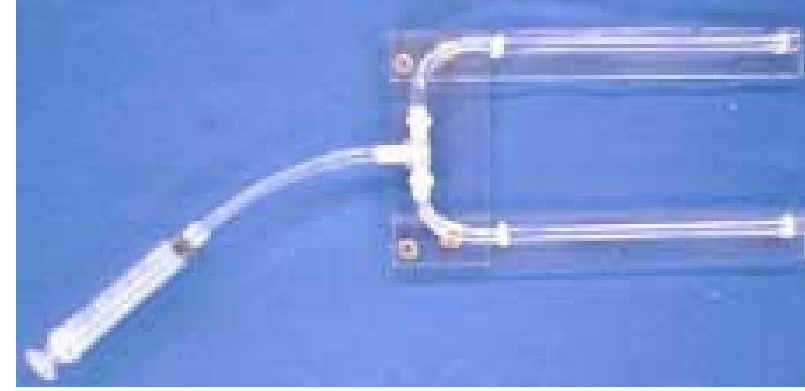

Figura 8. Forma final do densímetro.

\section{Funcionamento}

Este instrumento funciona utilizando-se o Princípio de Stevin ( Princípio Fundamental da Hidrostática ). Ao colocarmos cada um dos ramos do densímetro em dois recipientes, um deles contendo água e o outro contendo o líquido o qual se quer determinar a densidade, (figura 9) puxa-se o êmbolo da seringa e medimos a altura alcançada pelos líquidos. Dessa forma, pode-se concluir, a partir do princípio de Stevin, que se dividirmos a altura da coluna de água pela altura da coluna do outro líquido, o resultado obtido será a densidade do líquido em relação à água. Algebricamente:

$$
\frac{\rho_{l}}{\rho_{a}}=\frac{h_{a}}{h_{l}}
$$

Esse resultado torna-se válido também quando usamos qualquer outro líquido ao invés de água.

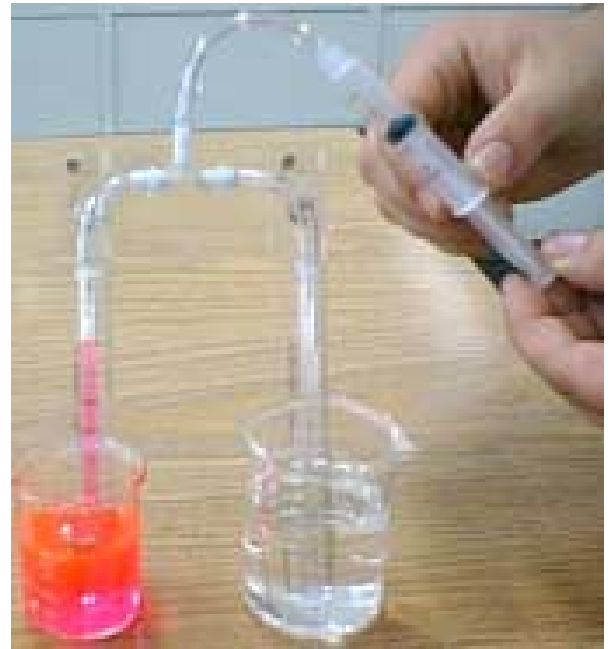

Figura 9. Aparato em funcionamento.

\section{Conclusão}

Apesar da simplicidade aparente do instrumento, é possível obter resultados bastante precisos. Quanto mais fina for a escala, maior será a sua precisão (como o resultado será dado em $\mathrm{g} / \mathrm{cm}^{3}$, sugere-se o uso de uma escala no mínimo, milimétrica, aumentando assim sua precisão). Ressalta-se apenas o cuidado com a limpeza adequada do instrumento, uma vez que líquidos de diferentes tipos podem reagir e danificar os materiais envolvidos. Para a medição de líquidos corrosivos, como ácidos, por exemplo, pode-se fazer um densímetro utilizando-se duas pipetas de vidro. Ainda sim, o devido cuidado deve ser tomado.

\section{Agradecimentos}

Ao Prof. Dr. Hamilton Araújo Bicalho (in memorian) que me incentivou a construir este instrumento.

Gostaria de expressar minha gratidão também ao Prof. Marcus Vinícius Prestes e ao Prof. Dr. Jair Lucinda pela revisão deste trabalho, e ao Prof. João Caputo e Oliveira e ao amigo Fábio Augusto Spina pelo trabalho de editoração e fotografia. 